\title{
Static Electrification of Pressboard/Oil Interface and Transient Phenomena
}

\author{
L. Peyraque \\ Jeumont Schneider Transformateurs, Lyon \\ A. Béroual and F. Buret \\ Ecole Centrale de Lyon, CEGELY, Ecully, France
}

\begin{abstract}
The static electrification phenomenon of insulating materials used in power transformers is investigated through two devices. The first is a cell with a rotating disk covered on both sides with a given pressboard and immersed in a metallic tank containing $\sim 41$ of oil; and second device enables us to measure the electrostatic charge tendency of oils. The electrostatic charge tendency (ECT) of insulating oils and the leakage current generated by the charge concentration gradient at the oil/pressboard interface are analyzed as function of temperature, water content and aging of oils, the nature of the pressboard, and the rotating speed of the disk. The influence of the surface roughness of the pressboard and antistatic additives on the aging and ECT also are considered. A correlation between ECT and the physico-chemical and electrical characteristics of the oil is established. It is shown that the temperature gradients and the water nigration phenomena at the oil/pressboard interface play an important role in the charge separation. Transient currents are strongly affected by the presence of air in the pressboard and the aging of the oil.
\end{abstract}

$\mathrm{T}$ HE phenomenon of static electrification resulting from oil flow through the insulated cooling ducts in power transformers constitutes currently a major problem for manufacturers and users. This is in relation with the numerous failures of power transformers, reported through the world and attributed to this phenomenon [1-3]. Indeed, the contact of streanhing high resistivity oil on the solid surface of the highly dried paper generates static electrification which can produce discharges and then affects the insulation design [4]. That is why knowledge of the physico-chemical characteristics of the dielectric materials used in such apparat is is essential for progress in the understanding of the static electrification phenomenon. Indeed, the latter depends on many parameters and especially on the behavior of these materials, whether these are used singly or in association (oil-pressboard).

This paper reports on the study of static electrification through measurements of the current $l_{L}$ that this phenomenon generates, and the electrostatic charge tendercy (ECT) of the oil and the behavior of the oil-pressboard. The influerce of various parameters such as streaming fluid velocity, temperature, age, water content and behavior of the insulating materials on ECT and $I_{L}$ is analyzed in both steady and transient regimes. A correlation between the electrostatic charge tendency, the leakage current, and the physicochemical and electrical characteristics of the oil is attempted.

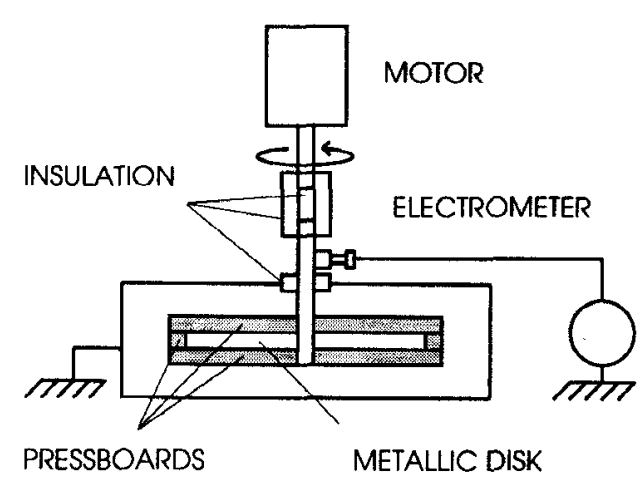

Figure 1. Rotating disk cell.

\section{EXPERIMENTAL TECHNIQUES}

Two experimental arrangements are used. The first one is a cell with a rotating disk, known as CIGRE test cell allowing us to measure the current induced by the charges created at the contact of insulating pressboards and oils. The second arrangement enables us to characterize the charging tendency of oils.

\subsection{ROTATING DISK CELL}

This resulted from experimental techniques used by petroleum industries and those used in the past by electrotechnic industries [5]. It 


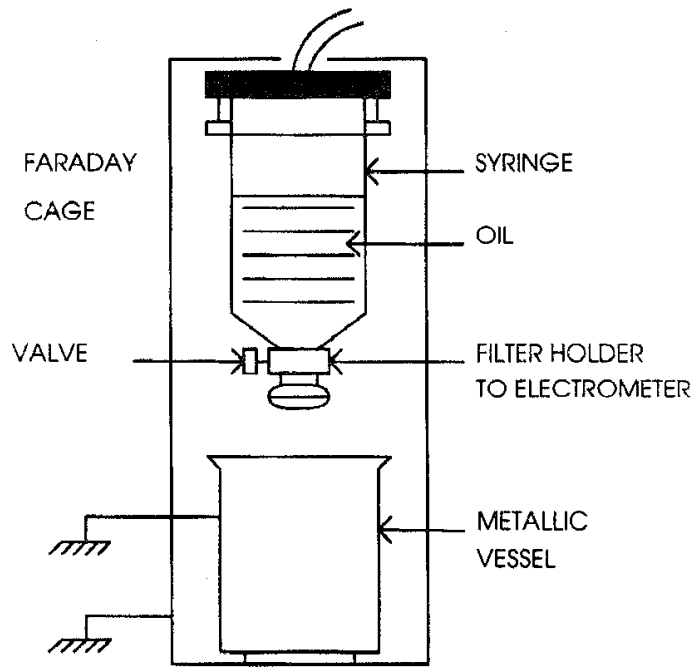

Figure 2. Charging tendency measuring apparatus.

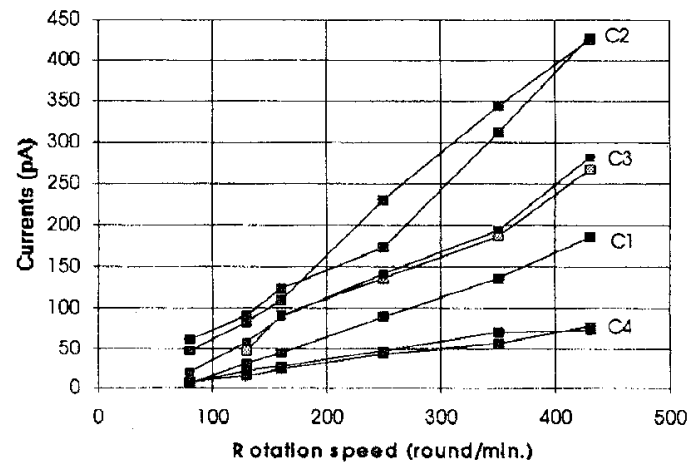

Figure 3. Comparison of insulating materials in aged oil.

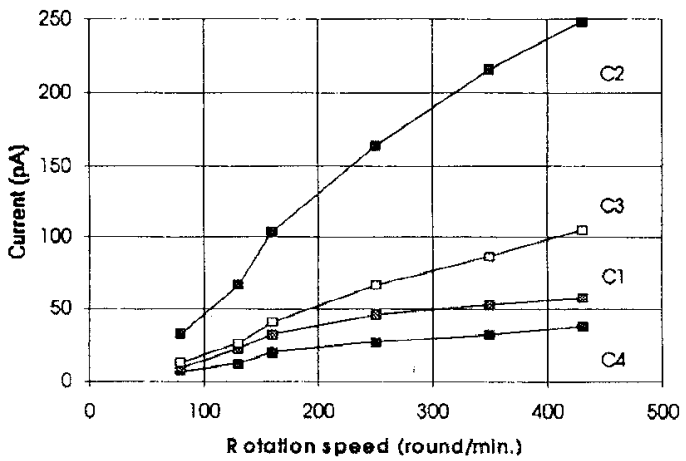

Figure 4. Comparison of insulating material in new oil.

consists of a disk of $150 \mathrm{~mm}$ diameter and $6 \mathrm{~mm}$ thickness, covered on both faces with pressboard and immersed in a metallic tank of $250 \mathrm{~mm}$ diameter and $80 \mathrm{~mm}$ height (Figure 1). The disk is placed at the center of the tank where it can be rotated by a small electrical motor. The tank as well as the rotating disk are made of aluminum. A heating system allowing temperatures between 20 and $90^{\circ} \mathrm{C}$ is used. This apparatus allows us to quantify the charge created at the pressboard/oil interface through a current measurement. Indeed, thanks to an electrometer inserted between the disk axis and the ground, we measure the current generated by the charge concentration gradient created at the pressboard/oil interface. This current $I_{L}$ called 'leakage current' is measured during a period of $30 \mathrm{~min}$; the transient current appearing just after the start of the disk rotation (i.e, the first $10 \mathrm{~min}$ of the test) is not taken into account. The CIGRE cell and the electrometer are placed in a Faraday cage.

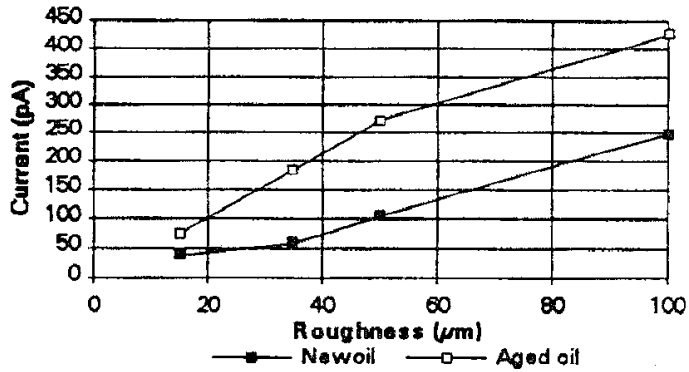

Figure 5. Influence of the roughness of the pressboard on electrification current with new and aged oils. The rotation speed is $430 \mathrm{rpm}$.

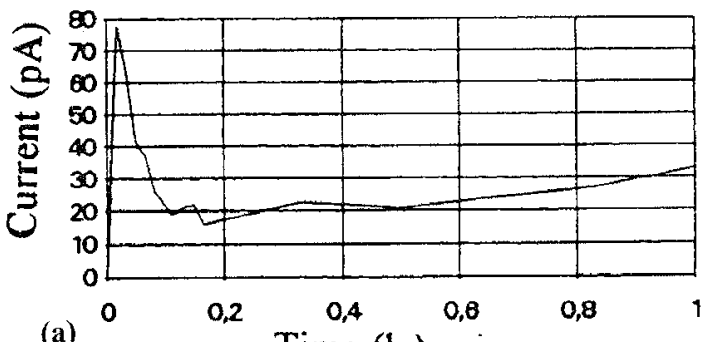

(a) Time $(\mathrm{h})$

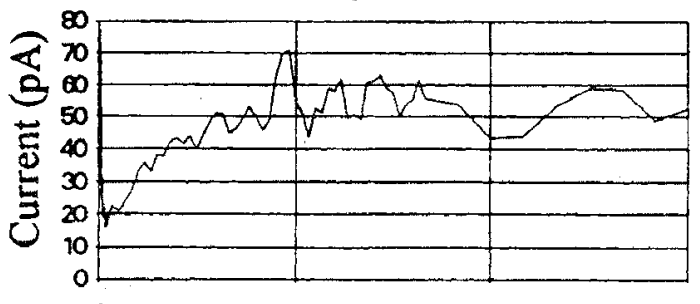

(b) 5 Time (h)

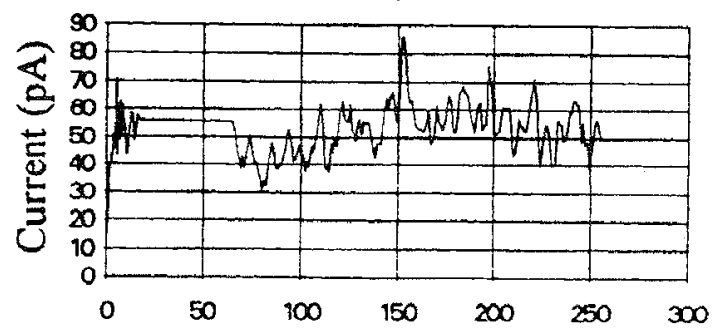

(c)

Time (h)

Figure 6. Continuous measurement during $1 \mathrm{~h}$ (a); $15 \mathrm{~h} \mathrm{(b);260} \mathrm{h} \mathrm{(c).}$ The rotation speed was $130 \mathrm{rpm}$.

\subsection{CHARGING TENDENCY APPARATUS}

To complete the above measurement, we use another arrangement allowing us to measure the ECT of a given oil when it passes through a cellulosic filter [6] (Figure 2). This allows us to compare the different oils and to correlate their charging tendency to their dielectric and chemical 
properties. Its working principle consists of forcing an oil, electrically neutral, through the filter, and results in a charge separation at the interface. The oil is positively charged and the filter negatively. The measurement is carried out by an electrometer on the metallic support surrounding the filter. This filter is a highly porous cellulose sheet (Whatman 541 type), normally $u$ sed to filter particles of $3 \mu \mathrm{m}$. It is changed at each new measurement

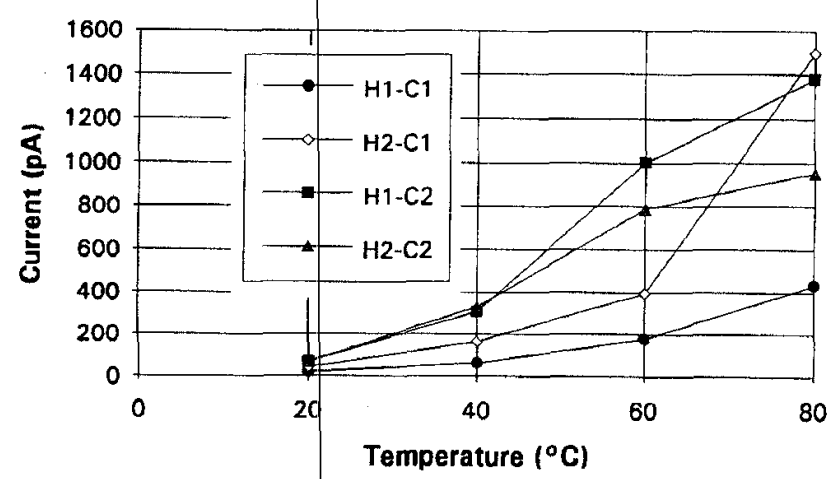

Figure 7. Effect of the temperature rise on the leakge current for different combinations of pressbcards ( $\mathrm{C} 1$ and $\mathrm{C} 2)$ and oils, with a rotating speed of $130 \mathrm{rpm}$.

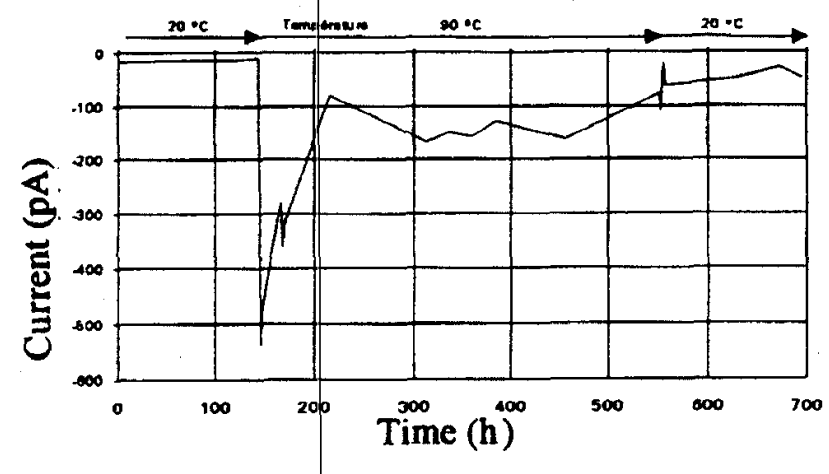

Figure 8. Effect of temperature gradient on pressboard $\mathrm{C} 1$ and new oil with a rotating speed of $130 \mathrm{rpm}$.

\section{RESULTS AND DISCUSSION 3.1 INFLUENCE OF THE INSULATING PRESSBOARD}

To compare the different pressboards which could be used in power transformers, four types of $2 \mathrm{~mm}$ thickness (a common thickness used in transformer) with different surface roughnesses are considered: 15 , 35,50 and $100 \mu \mathrm{m}$ corresponding respectively to $\mathrm{C} 4, \mathrm{C} 1, \mathrm{C} 3$ and $\mathrm{C} 2$. C4 is a synthetic material (consisting of aramid Nomex ${ }^{\mathrm{TM}}$ fibers); it creates few charges compared to cellulose materials.

The tests are achieved in the CIGRE cell, filling with two kinds of naphtenic oil: a new oil ( $\left.\mathrm{H}_{-}\right)$and an aged oil $(\mathrm{H} 2)$; the characteristics of these oils are given in Table 1 . With the aged oil, the tests are repeated two times. At each test, different oils and pressboards are used.

It appears from the experimental results that, for a given pressboard, the leakage current varies quasi-linearly with the disk rotation speed between 80 and $430 \mathrm{rpm}$ (Figures 3 and 4) confirming the results reported
Table 1. Characteristics of oils used in the tests.

\begin{tabular}{|c|c|c|c|}
\hline Oil & $\begin{array}{c}\mathrm{H}_{2} \mathrm{O} \\
\mathrm{ppm}\end{array}$ & $\begin{array}{c}\mathrm{ECT} \\
\mathrm{mC} / \mathrm{m}^{3}\end{array}$ & $\tan \delta$ \\
\hline New oil (H1) & 7 & 72 & $0.2 \times 10^{-4}$ \\
Aged oil (H2) & 5 & 66 & $2.8 \times 10^{-4}$ \\
\hline
\end{tabular}

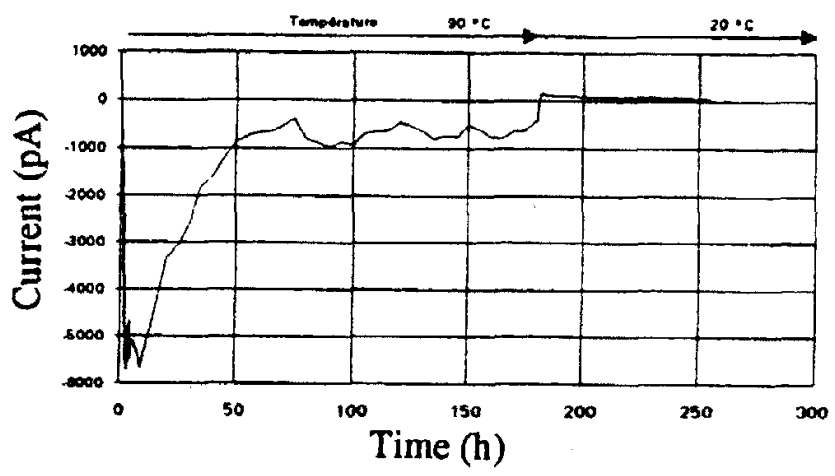

Figure 9. Effect of temperature gradient on pressboard C2 and aged oil with a rotating speed of $130 \mathrm{rpm}$.

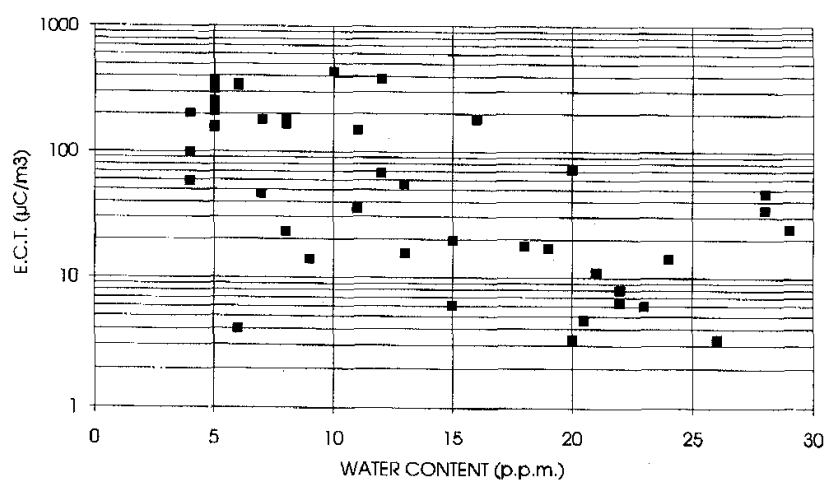

Figure 10. Influence of moisture on ECT of mineral insulating oils.

elswhere by us [7] and others [5,8]. This linear increase of the current has been attributed to the increase of the radial component of the circulating velocity of oil on the disk. Such a linearity has been observed also when studying laminar flow $[9,10]$. On the other hand, the pressboard $\mathrm{C} 2$ whose the surface roughness is $\sim 3 \times$ that of $\mathrm{C} 1$ creates a current 2.5 to $4 \times$ higher than $\mathrm{C} 1$; $\mathrm{C} 3$ which has a surface roughness $1.5 \times$ higher than $\mathrm{C} 1$ generates in its turn a current only 1.5 to $2 \times$ higher than $\mathrm{C} 1$. This linear variation tends to demonstrate that the smoothness of $\mathrm{C} 4$ is responsible for the very low current observed with this material. Note that similar variations have been obtained on the materials $\mathrm{C} 1, \mathrm{C} 2$ and $C 4$ on a tubular experimental arrangement $[10,11]$.

We also note a strong difference between the solid insulating materials with both new and aged oils. For given pressboard and rotating velocity of the disk, the aged oil gives a leakage current $\sim 2 \times$ that of virgin oil. Figure 5 gives the measured current $v s$. the surface roughness of pressboards in both oils, for a rotating speed of the disk of $430 \mathrm{rpm}$. One can note that the variation of the current is also quasi-linear, indicating the importance of the surface roughness of the pressboard. 


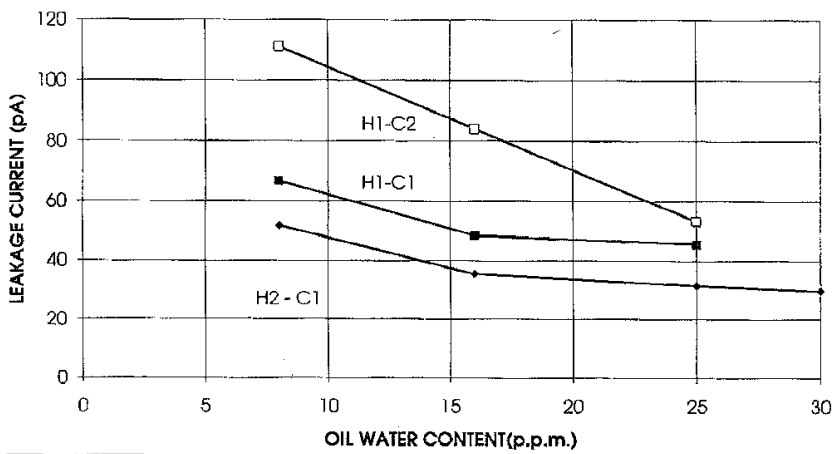

Figure 11. Leakage current vs. water content of oils with a rotating speed of $130 \mathrm{rpm}$.

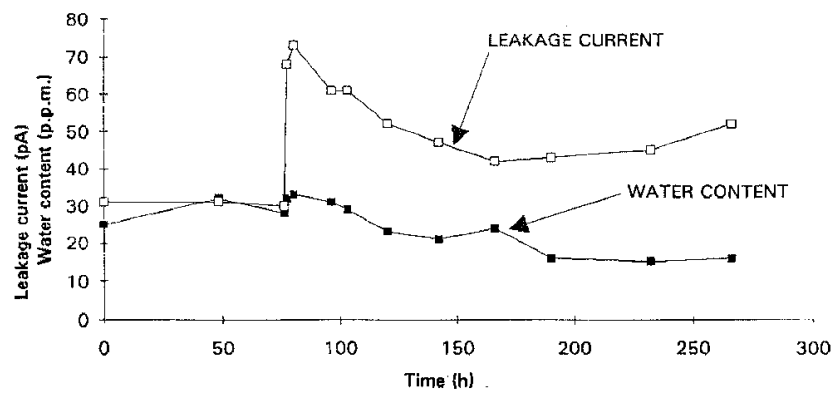

Figure 12. Transient current for a dried pressboard immersed in a wetted oil with a rotating speed of $130 \mathrm{rpm}$.

\subsection{TEMPERATURE GRADIENT AND TRANSIENT EFFECTS}

\subsubsection{STEADY STATE AT ROOM TEMPERATURE}

By carrying tests at room temperature during a period of $260 \mathrm{~h}$, with a constant rotation speed of $130 \mathrm{rpm}$, we observe three phases in the evolution of the leakage current (Figure 6). During the first $10 \mathrm{~min}$, an. important peak appears on the leakage current.

After this peak, the current increases slowly during a longer period ( 3 to $4 \mathrm{~h}$ ). This period corresponds to the thermal time constant of the insulating oil. Thus the slow increase of the current probably is due to internal heating induced by the movement of the disk. From $4 \mathrm{~h}$ after the beginning of the test to the end of the test $(260 \mathrm{~h})$, the current is stable at a fixed value.

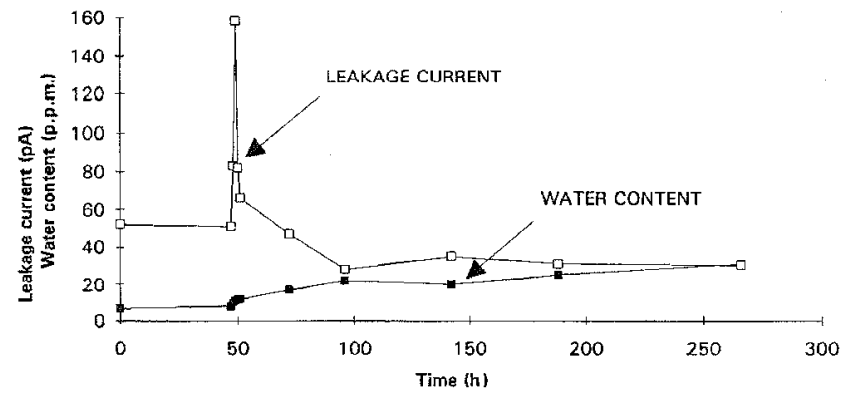

Figure 13. Transient current for a wetted pressboard immersed in a dried oil with a rotating speed of $130 \mathrm{rpm}$.

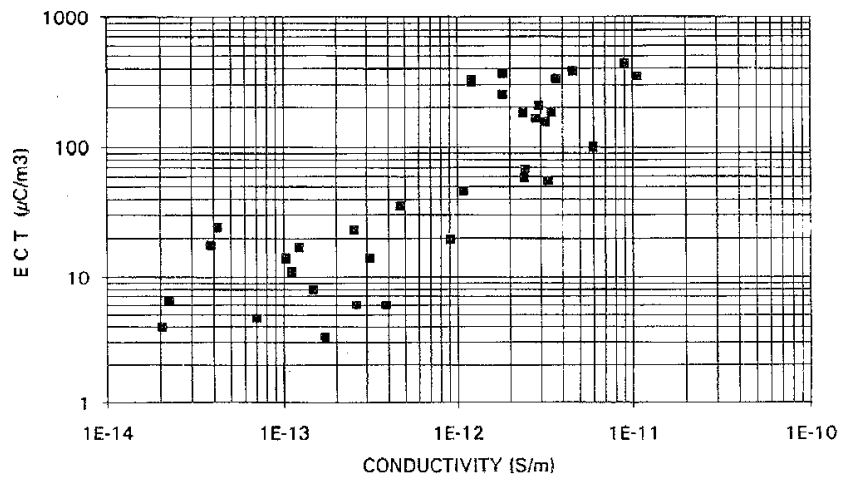

Figure 14. ECT of mineral oils vas, the conductivity at ambient.

\subsubsection{THE INTERFACE AND TEMPERATURE GRADIENT}

With a new oil, the leakage current also increases with the temperature as reported previously [7]. Figure 7 shows the influence of the temperature rise on the leakage current for different combinations of pressboards (C1 and $\mathrm{C} 2$ ) and oils ( $\mathrm{H} 1$ and $\mathrm{H} 2)$, in the range 20 to $80^{\circ} \mathrm{C}$, on a short period of $4 \mathrm{~h}$ with a rotating test cell of $130 \mathrm{rpm}$.

Now, if we apply a longer heating period at $90^{\circ} \mathrm{C}$, with nitrogen gas in the upper tank of the cell to avoid a degradation of the oil, the behavior will be different. Figure 8 gives the results obtained with the new oil and pressboard $\mathrm{C} 1$. The same tests had been carried out with pressboard $\mathrm{C}$, and a slightly aged oil (Figure 9).

From these tests, we can deduce that the leakage currents consists of three phases following a rise in the oil temperature: a strong rise of the current over a short period of $10 \mathrm{~h}$; a slow decrease during 60 to $80 \mathrm{~h}$ and a stable value higher than that observed at room temperature.

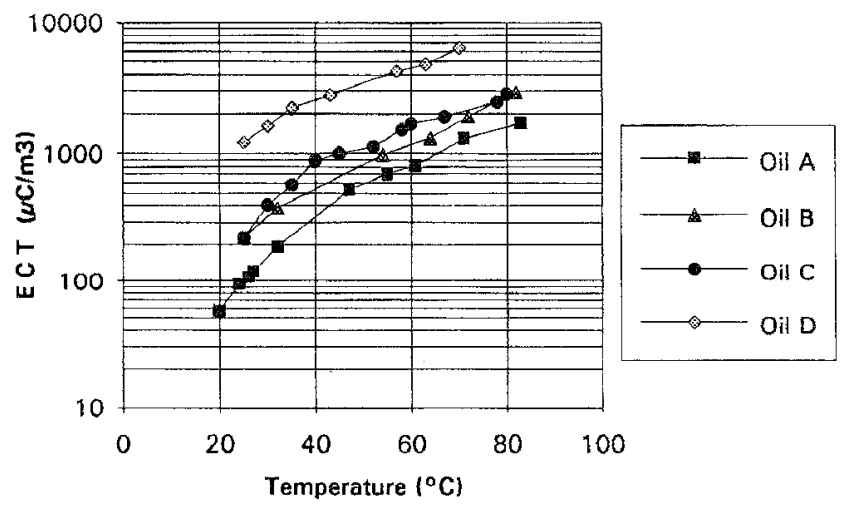

Figure 15. Variation of ECT of oils vs. temperature.

The first phase seems to be due to the migration of water from the surface of the pressboard to the oil, leading to a strong dryness at the surface of the pressboard. In the second phase, a new hygrometric equilibrum is created. When this equilibrum is reached, the current is stabilized. A similar phenomenon has been observed in a Couette charger cell [3].

Note that this effect has been observed only with new oils. The tests achieved on oils previously submitted to aging cycles do not show such a transient phenomenon, i.e., a high increase in the current during the first hours following the temperature increase [12]. 


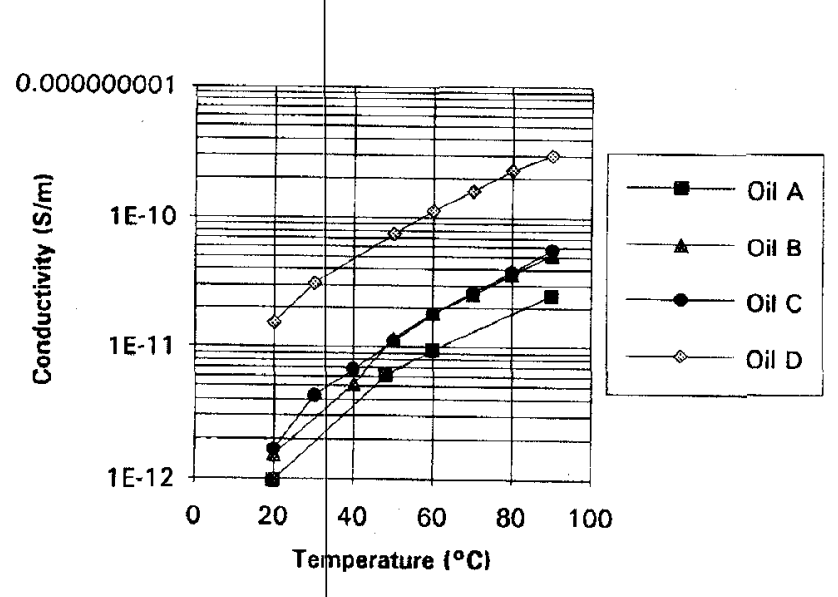

Figure 16. Variation of the conductivity of oils $v s$. temperature.

\subsubsection{MOISTURE EFFECT INFLUENCE ON ECT OF OIL}

Generally, oils with a high water content have a weak ECT. For usual water contents, i.e., $<10 \mathrm{ppm}$, the dispersion of measured values is important enough (Figure 10). Contrary, ECT seems to be limited at values $<100 \mu \mathrm{C} / \mathrm{m}^{3}$ for high water contents, i.e., $>20 \mathrm{ppm}$. Similar results have been obtained elsewhere $[6,13]$.

\section{INFLUENCE ON LEAKAGE CURRENT}

The leakage currents are affected by the dryness of pressboard and oil, and the filtration of oil. Figure 11 gives the variation of the leakage current, measured on the rotating test cell at a constant speed of $130 \mathrm{rpm}$, for three pressboard/oil couples (H1-C1, H1-C2 and H2-C2; $\mathrm{C} 1, \mathrm{C} 2, \mathrm{H} 1$ and $\mathrm{H} 2$ have been described above) upon the oil water content. We observe that the influence of the water content is relatively moderated when the pressboard and the oil are at the hygrometric equilibrum, as reported by Raduan [14].

The charge generated decleases when the water content is increased. These results confirm those obtained with the electric charge tendency. However, this influence remains smooth compared to the influence of the temperature, the conductivity, or the velocity.

\section{MOISTURE TRANSIENT PHASES}

Using the rotating disk cell, two types of tests were achieved. The first one consists in immersing a dried pressboard in a wet oil, and the second one consists in immersing a wet pressboard in a dried oil. Such tests enable us to analyze the charge quantities generated when hygrometric imbalance between pressboard and oil occurs. Figure 12 represents the transient currents observed on a dried pressboard $(<1 \%$ water content) in a wet aged oil ( $32 \mathrm{ppm})$.

The dryness of the pressboard first leads to a strong increase of the generated charge level. During the second stage (between 75 and $150 \mathrm{~h}$ ), there is water migration from the oil towards the pressboard and the charge separation decreases. Then, when the hygrometric equilibrum is reached, the current stabilizes around a value roughly higher than the initial one since the global water content of the pressboard/oil couple is weak.

Contrary, if we insert a wet pressboard in a dried oil, we obtain a fast decrease in the current (Figure 13). Finally, the current will stabilize around a value lower than the initial one because of the increase of
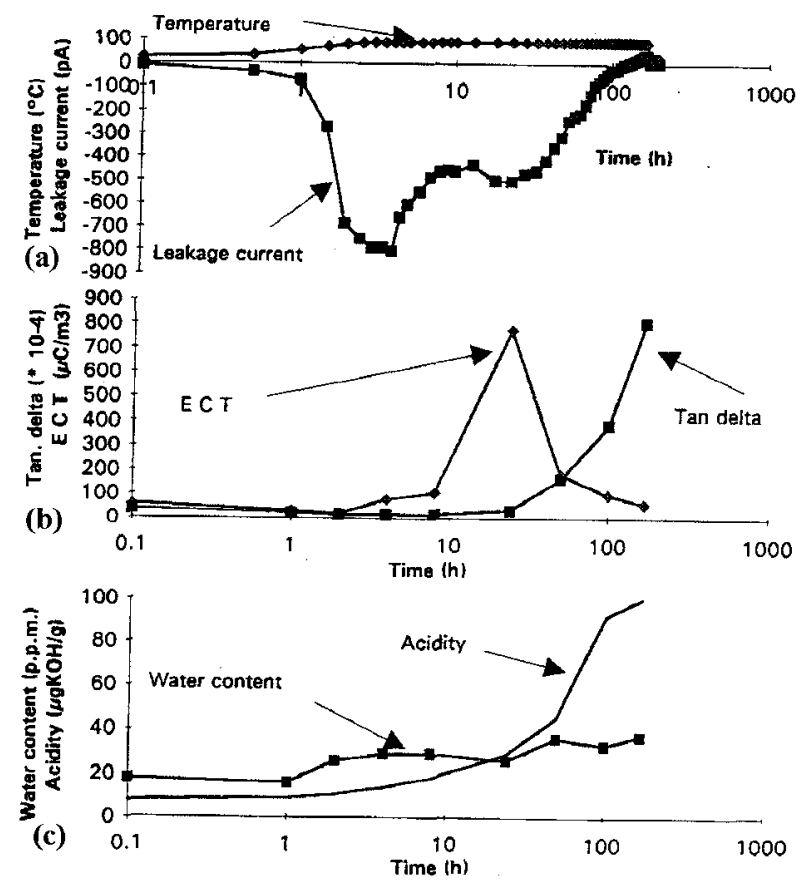

Figure 17. Characteristics of aging in absence of copper and BTA: (a) Evolution of the leakage, rotating speed of $130 \mathrm{rpm}$; (b) Evolution of dielectric loss and charging tendency on aging oil; (c) Acidity and water content of oil during the aging test.

the mean water content of the pressboard/oil couple. However, we observe an important peak on the transient current during $4 \mathrm{~h}$, before the expected diminution of the current. This peak may be due to the injection of air contained in the immersed pressboard.

\subsubsection{CORRELATION BETWEEN CONDUCTIVITY, TEMPERATURE AND ECT}

The conductivity of oil is certaintly the most important physicochemical parameter. It varies enormously during the aging process. According to Heydon et al. [15], the variation of the conductivity obeys an increasing exponential law in the range 20 to $90^{\circ} \mathrm{C}$.

Figure 14 gives the variation of ECT $v s$. the conductivity of oils at ambient. We observe that the charge tendency is lower when the conductivity is weak, i.e., for oils having weak dielectric losses and then for new oils. This is well verified for oils having low ECT. Such results have been reported by others $[16,17]$.

The electric charge tendency also increases with temperature. Figure 15 gives the variation of $\mathrm{ECT}$ vs. the temperature for four naphtenic oils A, B, C and D, where A is a new oil (virgin), B is an oil sampled on a new transformer, $C$ is a moderate aged oil and $\mathrm{D}$ a strongly aged laboratory oil. Note that the increase of ECT with temperature follows a law similar to that of the increase of the conductivity vs. the temperature (Figure 16).

\subsubsection{BEHAVIOR OF AGING OIL}

To determine the evolution of the electrostatic characteristics of the oil and the interface oil-pressboard, simulating the aging of the insulation of several years, we carry out a simulation on a total duration of $168 \mathrm{~h}$. During this test, 3.51 of oils are placed in the CIGRE cell, where it 

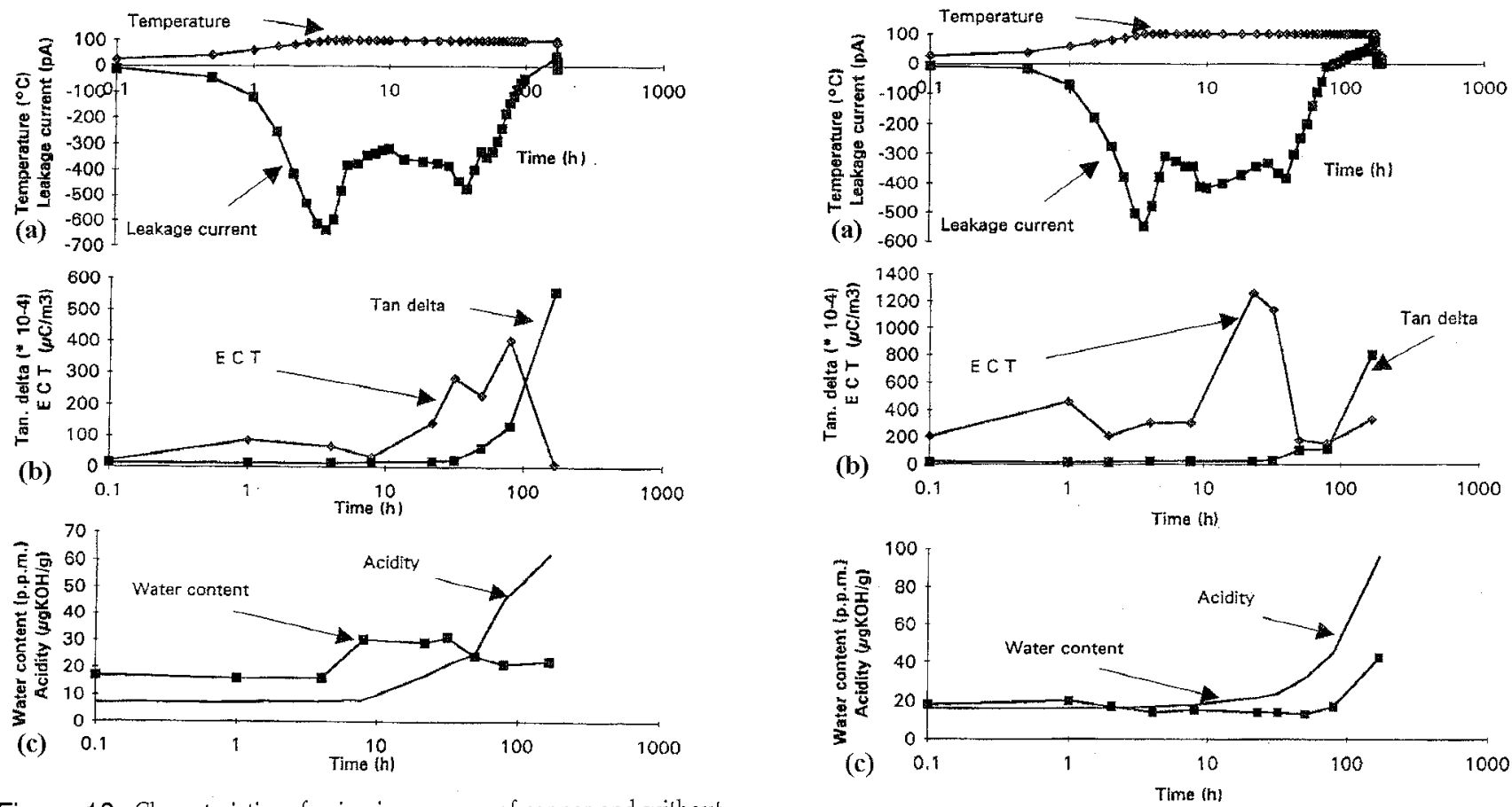

Figure 18. Characteristics of aging in presence of copper and without BTA: (a) Evolution of the leakage current, rotating speed of $130 \mathrm{rpm}$; (b) Evolution of dielectric loss and charging tendency on aging oil; (c) Acidity and water content of oil during the aging test

is heated at a constant temperature of $100^{\circ} \mathrm{C}$. Oxygen gas is continuously injected at a flow rate of $200 \mathrm{ml} / \mathrm{min}$. The new oil thus is progressively degraded.

During the test, we measure the leakage current for a constant rotating speed of $130 \mathrm{rpm}$. the oil is sampled regularly to measure the ECT, the total acidity and the dielectric losses $(\tan \delta)$.

Three aging tests are performed. The first one without benzotriazol (BTA), and without copper; the second one without BTA and with a copper wire of $2 \mathrm{~mm}$ diameter and $4.5 \mathrm{~mm}$ length; and the last one in presence of the same quantity of copper and $14 \mathrm{ppm}$ of BTA. Figure $17 \mathrm{sum}$ marizes the test results without copper and/or BTA. Figure 18 corresponds to the case with copper without BTA, and Figure 19 corresponds to the case with both copper and BTA. These three tests show a first peak on the currrent during the rise of the temperature which can be attributed to the migration of water from the cellulose surface towards the oil. Then, at $\sim 30$ to $60 \mathrm{~h}$, a second peak accompanied by a higher charging tendency occurs. At the end of the aging, the conductivity of the oil is so high that the leakage current measured on the CIGRE cell and the ECT are very low. We also note that BTA leads to a reduction of the first peak on the leakage current but it seems that it does not reduce the ECT of the oil. The influence of the copper is quite low on the aging process and on the behavior of the oil-pressboard interface.

\section{CONCLUSION}

I T appears from the experimental results that the leakage current characterising the electrostatic charge, increases quasi-linearly with the velocity of the rotating disk, the surface roughness of the insulating solid and the temperature. The effect of the temperature gradient and the aging of oil have been investigated. It is shown that the most dangerous

Figure 19. Characteristics of aging in presence of copper and $14 \mathrm{ppm}$ of BTA: (a) Evolution of the leakage current, rotating speed of $130 \mathrm{rpm}$; (b) Evolution of dielectric loss and charging tendency on aging oil; (c) Acidity and water content of oil during the aging test

situation, in the viewpoint of the static electrification, is the one corresponding to an increase in temperature. Transient effects due to the migration of the water at the interface and to the injection of air in pressboard seem to be of a great importance in the static electrification process. During the aging process of the oil, the charging tendency crosses through a maximum value, then decreases even if the conductivity continues its increase. For very aged oils, the conductivities are high, and the risk of static electrification is low.

\section{REFERENCES}

[1] D. W. Croft, "The static electrification phenomena in power transformer", IEEE Trans. Electr. Insul., Vol. 23, pp. 137-146, 1988.

[2] M. Higaki, T. Iss, T. Okada, K. Kurita, R. Tamura and H. Murata, "Reliability improvement of $500 \mathrm{kV}$ large capacitor power transformer", WG 12-02, CIGRE 1978.

[3] S. R. Lindgren, A. P. Washabaugh, M. Zahn, M. Brubaker, P. von Guggenberg and J. K. Nelson, "Temperature and Moisture Transient Effects on Flow Electrification Effects in Power Transformers", CIGRE, WG 15/12-02, Session 1992.

[4] M. Higaki, M. Miyao, K. Endo and H. Ohtani, "A calculation of potential distribution caused by static electrification owing to oil flow in oil-paper insulation system and its application to partial discharge phenomena in oil", IEEE Transactions on Power Apparatus Systems, Vol. 98, pp. 1275-1282, 1979.

[5] G. Praxl and W. Schobel, "Screening of material focused on electrification of solid/ oil interfaces used in power transformers", CIGRE, SC 12/15, JWG 13, TF 01, 1990.

[6] T. V. Oommen and E. M. Petrie, "Electrostatic Charging Tendency of Transformer Oils", IEEE Trans. on Power Apparatus \& Systems, Vol, 103, pp. 1923-1931, 1984.

[7] L. Peyraque, A. Béroual, C. Boisdon and F. Buret, "Phénomènes d'Electrisation des Matériaux Isolants pour Transformateurs de Puissance", Journal de Physique III, Vol. 4, no. 7, pp. 1295-1304, 1994.

[8] J. Kedzia, "Investigation of Transformer Oil Electrification in a Spinning Disk System", IEEE trans. Electr. Insul., Vol. 2, pp. 59-65, 1989. 
[9] T. V. Oommen and S. R. Lindgren, "Streaming electrification study of transformer system using a paper tube rnodel", IEEE Trans. on Power Delivry, Vol. 5, pp. 972982, 1990 .

[10] H. P. Moser, C. H. Krause, G. Praxl, G. Spandonis and R. Stonitsch, "Electrostatic Charging in Large Size Models of Power Transformer Cooling Ducts", CIGRE, Session 1992, JWG 12/15, TF 01- TF 02.

[11] H. P. Moser, C. Krause, G. Praxl, G. Spandonis, R. Stonitsch and H. Brechna, "Influence of Transformer Board and Nomex Board on Electrification of Power Transform ers", 3rd EPRI Workshop, San Jose, California, USA, January 1992.

[12] L. Peyraque, Study of static electrification phenomena induced by oil flow in power tranformers, PhD thesis, Lyon, France, 1995.

[13] H. Okubo, M. Ikeda, M. Horda and T. Yanari, "Charging tendency measurement of transformer oil", pp. 1-8. IEEE Power Engineering Society, Winter Meeting, February 1979.

[14] R. M. Radwan, R. M. El-Dewieny and I. A. Metwally, "Investigation of Static Electri- fication Phenomenon due to Oil Flow in Electrical Power Apparatus", IEEE Trans. Electr. Insulation, Vol. 27, pp. 278-286, 1992.

[15] R. G. Heydon and H. K. Welsh, "The Effect of Temperature and Time on the Dielectric Loss Tangent of Insulating Oils", CIGRE, WG 15-02, TF 04, Session 1994.

[16] S. Shimizu, H. Murata and M. Honda, "Electrostatics in Power Transformers", IEEF Trans. Power Apparatus \& Systems, Vol. 98, pp. 1244-1250, 1979.

[17] R. Tamura, Y. Miura, T. Watanabe, T. Ishi, N. Yamada and T. Nitta, "Static Electrification by Forced Oil Flow in Large Power Transformer", IEEE Trans. Power Apparatus \& Systems, Vol. 99, pp. 335-343, 1980.

This paper is based on a presentation given at the 12th International Conference on Conduction and Breakdown in Dielectric Liquids, Roma, Italy, 15-19 July 1996.

Manuscript was received on 24 February 1997, in final form 13 April 1998. 